No letter should be more than 400 words.

For letters on scientific subjects we normally reserve our correspondence columns for those relating to issues discussed recently (within six weeks) in the BMF.

We do not routinely acknowledge letters. Please send a stamped addressed envelope if you would like an acknowledgment.

- Because we receive many more letters than we can publish we may shorten those we do print, particularly when we receive several on the same subject.

\section{Well users clinic for illicit drug users}

SIR, - The Advisory Council on the Misuse of Drugs recommended last month that drug services should "have the capacity to respond to increased numbers of ill drug misusers" (recommendation 1 ) and should provide "on-site access to a medical practitioner with experience of treating HIVdisease" (recommendation 29).'

We are currently setting up a walk in clinic that provides general health care for this often disenfranchised group. Although general practitioners and general hospital doctors have been exhorted to provide for the general health care needs of drug users, ${ }^{1.3}$ our experience is that our patients who use drugs have received low levels of general medical care. This discrimination on grounds of diagnosis goes some way to explaining why hepatitis B immunisation programmes for drug users have not been introduced in the same way as those for other high risk groups (for example, homosexuals). ${ }^{4}$ We will introduce such an immunisation programme for hepatitis B negative drug users within the next few months, with the new genetically manufactured hepatitis $B$ vaccine (Engerix B)

We agree with Masters and Livingstone that primary care services have a vital role in the general health care of the population at risk for hepatitis B. This includes intravenous drug users and their families and close contacts. An effective response in this group of patients will require coordinated shared care between primary care and specialist services.

Last month we started the first weekly walk in clinic. This has been developed in collaboration with and is located in the premises of a local non-statutory drug agency. Within two weeks of starting, the clinic has proved its worth. A drug user was directed by a community worker to the clinic for a check up. Despite an initial history of not sharing needles and syringes and a negative HIV antibody test result two years previously he nevertheless presented with evidence of advanced HIV disease. On further questioning he reported sharing equipment when in prison two years previously. His presenting complaint of painful throat and sore mouth and tongue were found on examination to be related to oral candidiasis. He had swollen lymph nodes in his neck, loss of energy, and had lost about $4.5 \mathrm{~kg}$ in weight in the past month. A fuller examination and consideration of treatment was arranged at the local HIV centre, where he was seen the next day.

This young man seemed grateful for the opportunity to talk about his physical deterioration with a doctor. Even with non-medical drug workers who know about AIDS and notwithstanding the large influence of social factors on the development of drug problems many drug users prefer to discuss their medical problems confidentially with a doctor. Development of medical input into drug services in the United Kingdom has been most notable by its absence despite the appreciable expansion that has occurred in drug services during the 1980s and in drug and HIV services more recently. If assessment of the immune state of drug users and monitoring of their compliance with anti-HIV treatments are to become part of the work of drug services in the future, then additional medical input into all drug services will be required to provide adequate and appropriate health care.

J STRANG

MICHAEL ORGEL MICHAEL FARRELL

Drug Dependence Clinical Research and

Treatment Unit,

Maudsley Hospital,

London SE5 $8 \mathrm{AZ}$

1 Advisory Council on the Misuse of Drugs. AIIDS and drug misuse: part 2. London: Department of Health, 1989.

2 Department of Health and Social Security. Guidelines of good clinical practice in the treatment of drug misuse: report of the medical working group on drug dependence. London: Department of Health and Social Security, 1984.

3 Advisory Council on the Misuse of Drugs. AIDS and drug misuse: part 1. London: Department of Health, 1988.

Loke RHT, Murray-Lyon IM, Balachandran T, kvans BA. Screening for hepatitis $B$ and vaccination of homosexual men. Screening for hepatitis

5 Master N, Livingstone A, Cencora V. Hepatitis B: prevention in primary care. Br Med F 1989:298:908.

\section{Cardiac cathèterisation as an outpatient procedure}

SIR, - After reading the paper by Dr K G Oldroyd and colleagues' ${ }^{\prime}$ we reviewed our data on patients catheterised by the Judkins technique presenting as day cases to the day bed unit at Hammersmith Hospital between 14 September 1988 and 14 April 1989.

Two hundred patients were investigated by left heart catheterisation. They were catheterised during the morning session and, after haemostasis was secured by pressure, returned to the unit for observation. Heart rate and blood pressure were monitored at $\mathbf{3 0}$ minute intervals for the first four hours with the patients recumbent. The patients were then seated for a further two hours before being examined by a doctor and discharged if they were well. All patients were discharged with a hip spica bandage applied for 24 hours.

Of the 200 patients, 192 were discharged the same day. Three patients were not discharged because of unforeseen problems with transport, one with chronic renal failure was admitted for overnight observation (there were no complications), and one was kept overnight after an episode of asystole during the right coronary artery injection. Of the remaining three patients, one sustained a haematoma at the site of arterial puncture, one had prolonged chest pain which resolved without complication, and one suffered a dominant occipital lobe infarct, presumed to be embolic, which resulted in a partial residual visual defect. There were no deaths, no myocardial infarctions, and no need for emergency coronary artery bypass grafting.

The rate of complications was low not only in comparison with that reported by Dr Oldroyd and colleagues but also with that in a recent comparison of inpatient and outpatient catheterisation by Block et al. ${ }^{2}$ In both series an arterial sheath was used routinely. Although the study by Block et al supported outpatient catheterisation on the grounds of a low rate of complications for acute myocardial infarction and rhythm disturbances, comparable with that with inpatient procedures, and of finance, the rate of local vascular complications was higher $(12 \% v 8 \cdot 5 \%)$. $^{2}$

All of our procedures were performed using 7 or 8 French gauge catheters, and in fewer than 5\% of cases a haemostatic arterial sheath was used. Although our number of procedures is small (but similar to that of outpatient procedures reported by Block et $a l)$, the local rate of complications was low $(0.5 \%)$, implying that using an arterial sheath does not greatly affect the complication rate. Nevertheless, - catheterisation without an arterial sheath gives a further cost advantage. (A Cordis arterial sheath with side arm and dilator costs £14.95.)

NEAL G UREN PETER LUDMAN C NEWMAN

T CRAKE JOHN G F CLELAND

Department of Cardiology

Hammersmith Hospital,

London W' $120 \mathrm{HS}$

1 Oldroyd KG, Phadke KV, Phillips R, Carson PHM, Clarke M, Davis JAS. Cardiac catheterisation by the Judkins techinique as
an outpatient procedure. Br Med $\mathcal{F}$ 1989;298:875-6. (1 April.)

2 Block PC, Ockene I, Goldberg RJ, et al. A prospective randomized trial of outpatient versus inpatient cardiac catheterisation. trial of outpatient versus inpatien

\section{Training for coronary angioplasty}

SIR, - Dr Walker has drawn attention to a possible discrepancy between Minerva's note' on the TIMI II trial published in the New England Fournal of Medicine $^{2}$ and my recommendations for future needs of coronary angioplasty in the United Kingdom. ${ }^{3}$

Perhaps by relying solely on Minerva's comments Dr Walker has missed an issue central to the TIMI II trial. TIMI II is the third (and largest) study to show that immediate angioplasty - that is, 